\title{
A Hepatocellular Carcinoma Patient with TSC1 Mutations Benefits from Treatment with Everolimus: A Case Report
}

\author{
Hua-Sheng Shi, ${ }^{a}$ Shuo Wang ${ }^{a, b}$ Man-Jiang Li ${ }^{a, b} \quad$ Li-Qun Wu $^{a, b}$ \\ ${ }^{a}$ Liver Disease Center, Affiliated Hospital of Qingdao University, Qingdao, PR China; ${ }^{b}$ Medical College of Qingdao \\ University, Qingdao University, Qingdao, PR China
}

\section{Keywords}

Everolimus · Next-generation sequencing · Hepatocellular carcinoma - Mammalian target of rapamycin - Targeted therapy

\begin{abstract}
Hepatocellular carcinoma (HCC) has a high degree of malignancy and poor prognosis. Treatment options for patients with advanced HCC are limited. There is currently no evidence to approve the accumulation of targeted therapies for $\mathrm{HCC}$ to support the inhibition of the PI3K/Akt/mTOR signaling pathway as an effective therapeutic strategy. We report on a patient with advanced HCC carrying the TSC1 gene mutation who responded well to the mammalian target of rapamycin inhibitor everolimus. Computed tomography revealed tumor shrinkage and maintenance of partial remission after everolimus treatment for $>12.3$ months. To the best of our knowledge, this is the first clinical case report showing benefit from everolimus treatment in HCC patients with TSC1 gene mutations. Therefore, everolimus may be used as a potential targeted therapy for HCC with TSC1 gene mutation.

(c) 2020 S. Karger AG, Basel
\end{abstract}

\section{Introduction}

Hepatocellular carcinoma (HCC) is the most common hepatic malignancy and ranks second in the world for tumor-related causes of death. In China, various liver diseases, mainly caused by chronic hepatitis B virus infection, have led to a high incidence of HCC. The incidence of HCC in both men and women in China ranks first in the world [1].

Mammalian target of rapamycin (mTOR) is a downstream signaling molecule in the PI3K/Akt/signaling pathway and plays an important role in regulating cell growth and proliferation. The mTOR inhibitor everolimus has been approved by the US Food and Drug Administration (FDA) for the treatment of advanced renal cell carcinoma and other cancer types. However, it is unclear whether everolimus is effective against $\operatorname{HCC}[2,3]$.

\section{Case Presentation}

The patient was a 47-year-old man. He had a history of hepatitis B for 3 years and was treated with antiviral entecavir. In October 2012, he underwent liver segment VI resection. Pathological reports showed poorly differentiated HCC, and immunohistochemical staining was positive for $\mathrm{Cx} 43$, epidermal growth factor recep- 


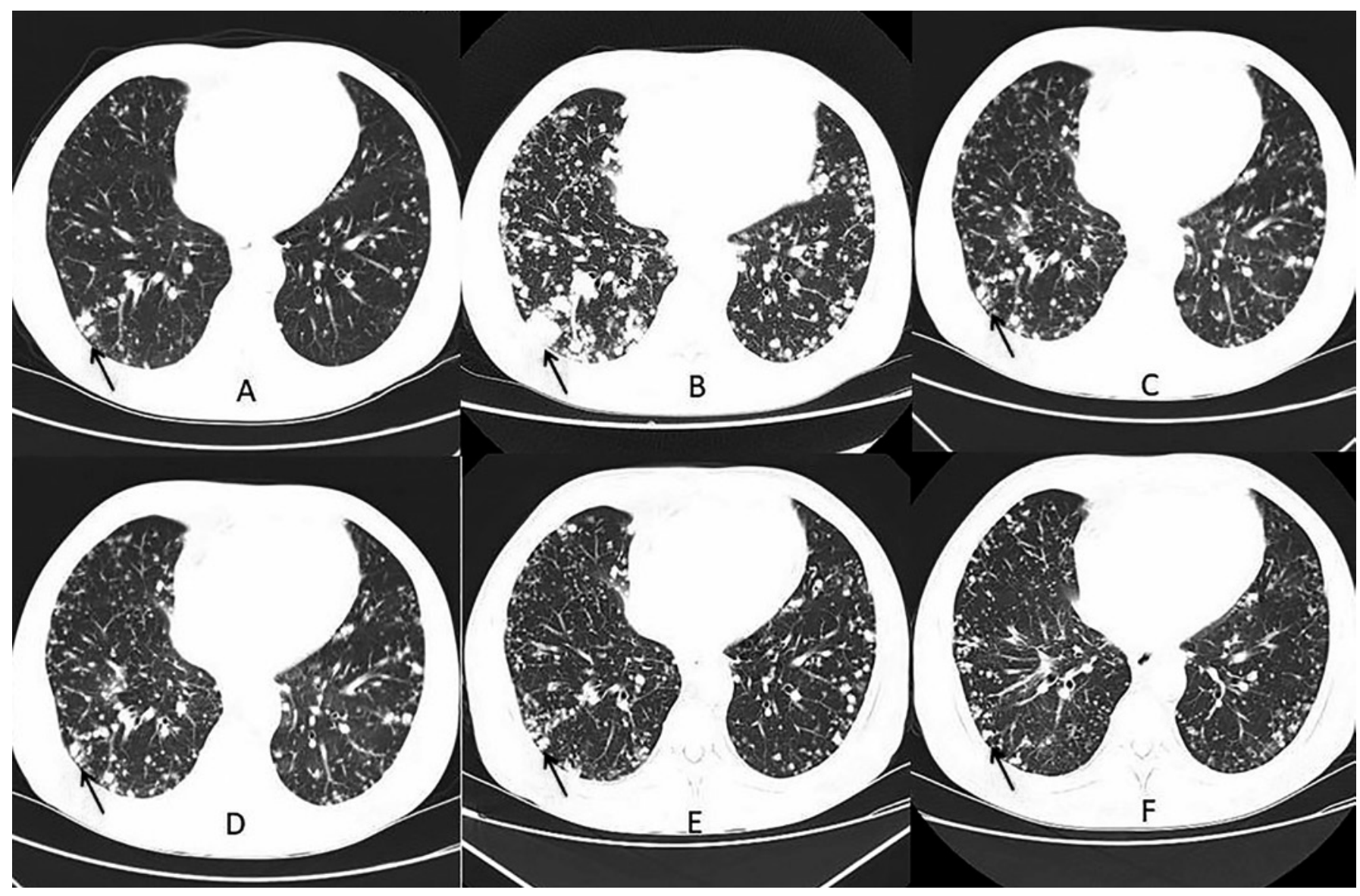

Fig. 1. A Before treatment with regorafenib. B Before treatment with everolimus. C-F Shrinkage of lung metastases after everolimus treatment is shown.

tor, CD147 and CD10, and negative for carcinoembryonic antigen, a-fetoprotein (AFP), and CK19. Since then, the patient has been followed up regularly. In a routine review in April 2017, the right hepatic caudate lobe tumor invaded the inferior vena cava. After multi-disciplinary treatment discussion, we recommended treatment with radiotherapy + sorafenib (400 mg daily). After 1 week of drug treatment, the skin of his palms and soles showed signs of erythema. This was accompanied by mild adverse effects such as nausea, vomiting, and diarrhea. Computed tomography (CT) in September 2017 showed an increase in hepatic caudate lobe tumors and tumor marker AFP was within the normal range. We recommended transarterial chemoembolization. In December 2017, in a CT scan of the lungs multiple nodules were detected (Fig. 1A), and the patient underwent CT-guided lung biopsy. The results showed lung metastasis from the liver tumor. He stopped taking sorafenib and started regorafenib (160 mg daily). After 5 months of treatment, the patient developed severe nausea and vomiting, diarrhea as well as liver function damage (alanine aminotransferase [ALT] $163 \mathrm{U} / \mathrm{L}$ and aspartate aminotransferase [AST] $125 \mathrm{U} / \mathrm{L}$ ) and other adverse effects. Chest CT showed continuous progression of lung metastases (Fig. 1B), and he stopped taking regorafenib.

There is currently no standard treatment for advanced HCC. For this patient, systemic chemotherapy was not indicated because of his poor physical condition. Therefore, we recommended nextgeneration sequencing. Next-generation sequencing was performed in May 2018 on the lung biopsy tumor tissue and tumor samples obtained at hepatectomy. We detected all types of genom- ic alterations, including base substitutions, insertions and deletions, copy number changes, and rearrangements in $>390$ genes. Five tumor-associated gene mutations were detected, including c.2626-2A > T mutation of TSC1 (NM_000368), c.-124C>T mutation of TRET (NM_001193376), K1807N mutation of ATM (NM_000051), W195* mutation of RB1 (NM_000321), and I509Mfs*23 mutation of PIK3R1 (NM_181523). Previous studies have shown that mutation of TSC1 can lead to activation of the $\mathrm{PI} 3 \mathrm{~K} / \mathrm{AKT} / \mathrm{mTOR}$ pathway, while mTOR inhibitor therapy may be effective [4], so the patient accepted mTOR inhibitor therapy with everolimus (10 $\mathrm{mg}$ daily).

After 12.3 months of treatment with everolimus, liver function tests showed total protein and albumin levels of 7.47 and $3.60 \mathrm{~g} / \mathrm{dL}$, respectively, bilirubin was within the normal range, and the ALT and AST levels were 37 and $48 \mathrm{U} / \mathrm{L}$, respectively. The liver function was significantly improved, and the tumor marker AFP was in the normal range. CT showed that the larger metastases in the lungs ranged from $27.53 \times 15.41 \mathrm{~mm}$ to $7.68 \times$ $4.95 \mathrm{~mm}$, and the number of tumors was significantly reduced. According to the evaluation criteria for the efficacy of solid tumor treatment, at the latest follow-up on May 20, 2019, the patient was considered to have achieved partial response. So far, no new tumor lesions have been detected on the patient's liver during the course of everolimus treatment. The tumor response as stable disease and progression-free survival were achieved after more than 12.3 months from the initial treatment with everolimus (Fig. 1C-F). The patient continues to take everolimus to the present time. 


\section{Discussion}

By performing a second-generation genetic test on tumor tissue, we detected five tumor-associated gene mutations: c.2626-2A $>$ T mutation of TSC1, c. $-124 \mathrm{C}>\mathrm{T}$ mutation of TERT, K1807N mutation of ATM, W195* mutation of RB1 and I509Mfs*23 mutation of PIK3R1. TSC1 is a tumor suppressor gene that exerts its function by negatively regulating the mTOR complex. Loss of TSC function leads to activation of the mTOR signaling pathway and promotes tumorigenesis and tumor progression [5]. Some studies have shown that TSC1/2 gene mutations have been reported in HCC, but the frequency of occurrence is low [6-8]. Another study reported that TSC1/2 gene mutation was detected in $16.2 \%$ (18/111) of patients with HCC associated with chronic hepatitis B virus [7]. Activation of TERT promotes unrestricted proliferation of tumor cells. Mutations in the promoter region of the TERT gene are present in most tumors [9-12]. ATM exerts tumor suppressor effects by regulating downstream genes such as TP53 and BRCA1 [13, 14]. RB1 is a tumor suppressor gene, and there is a loss of $R B 1$ function in various tumor types $[15,16]$. Mutation, deletion, or low expression of the PIK3R1 gene has been reported in breast, ovarian, endometrial, prostate, lung, colorectal, and bladder cancer [17-19]. There are currently no FDA-approved antitumor drugs targeting the TERT, ATM, RB1, and PI$K 3 R 1$ genes. The FDA has approved the mTOR inhibitor everolimus for the treatment of tuberous sclerosis (TSC)associated tumors, neuroendocrine tumors, renal cell carcinoma, and breast cancer. In a retrospective study, 1 patient with bladder cancer, carrying the TSC1 E636fs and NF2 S288* variants, received everolimus and achieved a complete response with a duration of $>2$ years [20].

We detected a TSC1 gene mutation in the patient's liver tumor tissue and lung biopsy tissue samples, which may cause activation of the mTOR pathway, leading to the development and progression of liver cancer, while the $\mathrm{mTOR}$ pathway inhibitor everolimus blocks activation of this pathway and inhibits tumor growth. Regarding our patient, this may be the main reason for the inhibition of tumor growth after the intake of everolimus. Of course, other anti-tumor mechanisms may be spontaneous resolution of HCC and delayed immune response after sorafenib and regorafenib treatment [21]. Our patient has been treated with sorafenib and regorafenib, which may alter the body's tumor microenvironment and immunity. In the past, there have been reports of delayed reactions after the intake of sorafenib. The patient discontinued the drug due to severe liver damage when taking regorafenib [22]. There were mild side effects, such as rash and diarrhea, during the course of everolimus intake, but everolimus therapy was not stopped.

In general, the prognosis of HCC is poor, and most patients with advanced liver cancer would not survive 1 year without treatment [23]. There is still no effective treatment for advanced liver cancer, and the available treatment is mostly systemic. At present, only sorafenib and regorafenib are approved by the FDA for targeted therapy of advanced liver cancer. Until now, no studies have shown that everolimus can significantly benefit patients with advanced liver cancer.

To the best of our knowledge, this is the first case report of a benefit from everolimus treatment of HCC with TSC1 mutation. However, whether the presence of mutations in the TERT, ATM, RB1, and PIK3R1 genes contributed to the treatment response remains unclear, and whether the patient's constitutional response to everolimus contributed to prolonging survival also remains unclear.

\section{Acknowledgement}

We thank the Department of Liver Disease Center, Affiliated Hospital of Qingdao University for this study.

\section{Statement of Ethics}

There were no patient identifiers, and verbal informed consent was obtained. The study was conducted in accordance with the ethical principles that have their origin in the Declaration of Helsinki. The Medical Ethical Committee of the Affiliated Hospital of Qingdao University (QYFY WZLL 25522) approved the study protocol.

\section{Disclosure Statement}

There are no potential conflicts of interest relevant to this article. No funding was received for this study.

\section{Author Contributions}

Hua-Sheng Shi wrote the case report. Li-Qun Wu critically revised the intellectual content and contributed to the design of the paper. Shuo Wang and Man-Jiang Li provided the collection of literature.

\section{References}

1 Torre LA, Bray F, Siegel RL, Ferlay J, LortetTieulent J, Jemal A. Global cancer statistics, 2012. CA Cancer J Clin. 2015 Mar;65(2):87108.

2 Pouliot F, Pantuck AJ. Words of wisdom. Re: Efficacy of everolimus in advanced renal cell carcinoma: a double-blind, randomised, placebo- controlled phase III trial. Eur Urol. 2009 Jun;55(6):1482-4.

3 Krueger DA, Care MM, Holland K, Agricola K, Tudor C, Mangeshkar P, et al. Everolimus for subependymal giant-cell astrocytomas in tuberous sclerosis. N Engl J Med. 2010 Nov; 363(19):1801-11. 
4 Moolthiya P, Tohtong R, Keeratichamroen S, Leelawat K. Role of mTOR inhibitor in cholangiocarcinoma cell progression. Oncol Lett. 2014 Mar;7(3):854-60.

5 Zhang Y, Gao X, Saucedo LJ, Ru B, Edgar BA, Pan D. Rheb is a direct target of the tuberous sclerosis tumour suppressor proteins. Nat Cell Biol. 2003 Jun;5(6):578-81.

6 Zucman-Rossi J, Villanueva A, Nault JC, Llovet JM. Genetic Landscape and Biomarkers of Hepatocellular Carcinoma. Gastroenterology. 2015 Oct;149(5):1226-1239.e4.

7 Ho DW, Chan LK, Chiu YT, Xu IM, Poon RT, Cheung TT, et al. TSC1/2 mutations define a molecular subset of HCC with aggressive behaviour and treatment implication. Gut. 2017 Aug;66(8):1496-506.

8 Totoki Y, Tatsuno K, Yamamoto S, Arai Y, Hosoda F, Ishikawa $S$, et al. High-resolution characterization of a hepatocellular carcinoma genome. Nat Genet. 2011 May;43(5):4649.

9 Huang FW, Hodis E, Xu MJ, Kryukov GV, Chin L, Garraway LA. Highly recurrent TERT promoter mutations in human melanoma. Science. 2013 Feb;339(6122):957-9.

10 Horn S, Figl A, Rachakonda PS, Fischer C, Sucker A, Gast A, et al. TERT promoter mutations in familial and sporadic melanoma. Science. 2013 Feb;339(6122):959-61.
11 Killela PJ, Reitman ZJ, Jiao Y, Bettegowda C, Agrawal N, Diaz LA Jr, et al. TERT promoter mutations occur frequently in gliomas and a subset of tumors derived from cells with low rates of self-renewal. Proc Natl Acad Sci USA. 2013 Apr;110(15):6021-6.

12 Vinagre J, Almeida A, Pópulo H, Batista R, Lyra J, Pinto V, et al. Frequency of TERT promoter mutations in human cancers. Nat Commun. 2013;4(4):2185.

13 Chyall LJ, Quigley KA, Still EJ. 4- [3- (4-cyclopropanecarbonyl-piperazine-I-carbonyl) -4 -fluoro-benzyl] -2H-phthalaz in-1-one. 2012. National Center for Biotechnology Information. PubChem Database. Patent=US8183369, https://pubchem.ncbi.nlm.nih.gov/patent/ US8183369 (accessed on May 13, 2020)

14 Ahmad SF, Zoheir KM, Ansari MA, Korashy HM, Bakheet SA, Ashour AE, et al. The role of poly(ADP-ribose) polymerase-1 inhibitor in carrageenan-induced lung inflammation in mice. Mol Immunol. 2015 Feb;63(2):394-405.

15 Manning AL, Dyson NJ. RB: mitotic implications of a tumour suppressor. Nat Rev Cancer. 2012 Feb;12(3):220-6.

16 Goodrich DW. The retinoblastoma tumorsuppressor gene, the exception that proves the rule. Oncogene. 2006 Aug;25(38):5233-43.

17 Cizkova M, Vacher S, Meseure D, Trassard M, Susini A, Mlcuchova D, et al. PIK3R1 underexpression is an independent prognostic marker in breast cancer. BMC Cancer. 2013 Nov; 13:545.
18 Taniguchi CM, Winnay J, Kondo T, Bronson RT, Guimaraes AR, Aleman JO, et al. The phosphoinositide 3-kinase regulatory subunit p85alpha can exert tumor suppressor properties through negative regulation of growth factor signalling. Cancer Res. 2010 Jul;70(13): 5305-15.

19 Sood A, McClain D, Maitra R, Basu-Mallick A, Seetharam R, Kaubisch A, et al. PTEN gene expression and mutations in the PIK3CA gene as predictors of clinical benefit to antiepidermal growth factor receptor antibody therapy in patients with KRAS wild-type metastatic colorectal cancer. Clin Colorectal Cancer. 2012 Jun;11(2):143-50.

20 Iyer G, Hanrahan AJ, Milowsky MI, Al-Ahmadie $\mathrm{H}$, Scott SN, Janakiraman $\mathrm{M}$, et al. Genome sequencing identifies a basis for everolimus sensitivity. Science. 2012 Oct;338(6104): 221.

21 Lam KC, Ho JC, Yeung RT. Spontaneous regression of hepatocellular carcinoma: a case study. Cancer. 1982 Jul;50(2):332-6.

22 Okuwaki Y, Nakazawa T, Hidaka H, Shibuya A, Koizumi W. Late-onset benefit in progressive advanced hepatocellular carcinoma with continued sorafenib therapy: a case report. J Med Case Reports. 2012 Jan;6(1):38.

23 Llovet JM, Brú C, Bruix J. Prognosis of hepatocellular carcinoma: the BCLC staging classification. Semin Liver Dis. 1999;19(3):32938. 